\title{
Safety in the Use of Explosives in Land Seismic Acquisition Operations in the Parnaíba Basin, State of Maranhão \\ Sandro Ferreira Miranda ${ }^{* 1}$, Enéas Macêdo dos Santos Neto ${ }^{1}$, Carlos Eduardo Siedschlag ${ }^{1},{ }^{1}$ Eneva S.A.
}

\section{Copyright 2021, SBGf - Sociedade Brasileira de Geofísica}

This paper was prepared for presentation during the $17^{\text {th }}$ International Congress of the Brazilian Geophysical Society held in Rio de Janeiro, Brazil, 16-19 August 2021.

Contents of this paper were reviewed by the Technical Committee of the $17^{\text {th }}$ International Congress of the Brazilian Geophysical Society and do not necessarily represent any position of the SBGf, its officers or members. Electronic reproduction or storage of any part of this paper for commercial purposes without the written consent of the Brazilian Geophysical Society is prohibited.

\section{Abstract}

This study has the relevance of addressing the legal requirements imposed by the Brazilian Army and the National Agency of Petroleum, Natural Gas and Biofuels (ANP), as well as the best practices disclosed by the International Association of Geophysical Contractors (IAGC), with the objective to propose safety measures to comply with applicable legislation and the prevention of accidents with workers and third parties involved with the use of explosives in the provision of services for the onshore seismic acquisition for exploration and production of oil and natural gas in Parnaíba Basin, State of Maranhão. Through an exploratory research method with a qualitative approach and based on experience and field observation, the results and discussion present the modus operandi of the seismic teams' activities for the handling, transport and storage of explosives and accessories, in a scenario that regulatory agencies are increasingly demanding safety and active inspection.

\section{Introduction}

The seismic data acquisition contributes to expand the geological knowledge of the sedimentary basins and is part of the chain of services developed in the Oil and Gas $(O \& G)$ industry.

In onshore seismic activities, detonations with explosive charges are used as artificial sources for the acquisition of seismic data, for subsurface mapping and prospect definition, which increases the chances of exploratory success for the discovery of the accumulations of oil and natural gas.

The explosives are classified as Controlled Products by the Brazilian Army (PCE) and provides strict rules for their handling, transport and storage, through the Regulation of Controlled Products, approved by Decree $N^{\circ} 10.030$, of September 30, 2019. In addition, they must observe the Resolutions of the National Agency of Petroleum, Natural Gas and Biofuels (ANP), which establish safety criteria for the transportation, storage, distribution, use and destruction of explosives.

The ANP, through the Superintendence of Operational Safety and Environment (SSM), establishes and supervises the rules for regulated companies to use best practices in the protection of human health and the environment. Each year, SSM has intensified its oversight activities in the operational security aspects. As disclosed in the Annual Report on Operational Security of the ANP in 2019, "[...] were carried out by SSM 91 preventive operational security inspections, the largest number since 2010" (ANP, 2020)

In the technical article on the "Panorama of Seismic Teams Safety in Brazil" of Brazilian Geophysical Society (SGBf), Vianna $(2014$, p. 31) reinforces that "Lately, both the Brazilian Army and the ANP have stepped up their monitoring and published stricter standards, mainly regarding the transportation, storage, handling and use of explosives."

Regarding the workplace safety, the use of explosives presents a high potential risk, which may result in material damage with total loss or cause serious injury and death to the people involved.

Therefore, the general objective of this work is to enlighten the main safety measures that should be practiced by Data Acquisition Companies (EAD) to meet the applicable regulations and standards of the current legislation, while adopting the best operational practices for accident prevention in the activities of handling, transport and storage of explosives, in the onshore seismic data acquisition located in the Parnaíba Basin, on the state of Maranhão side.

It is also worth mentioning that land seismic acquisition is an activity that is still little known by the community in general and that lacks the availability of academic material focused on its management.

\section{Method}

Based on the knowledge acquired in the seismic campaigns in the Parnaíba basin, safety measures and good practices in the oil industry will be established, in order to legally frame the activity and minimize the risks to the safety of the workers and third parties involved.

The scientific method used will be the inductive method, based on experience and, starting from data about work previously performed, to establish the general concepts (acting standard) in new work with similar characteristics. Through the direct monitoring of the authors in the seismic acquisition inspection activities, it will be possible to observe and analyze the facts to propose the application of actions related to the theme of the work. Documentary analysis and direct and participant observation will be the instruments for data collection. 
Below are listed the main documents of the current Brazilian legislation that will be the focus of discussion in this work.

- BRAZIL. decree No. 10,030, of September 30, 2019;

- BRAZILIAN ARMY. Ordinance No. 56-COLOG, of June 5, 2017;

- BRAZILIAN ARMY. Ordinance No. 147-COLOG, of November 21, 2019;

- national agency for petroleum, NATURAL GAS AND BIOFUELS. ANP Resolution No. 3 of 18 January 2012.

Oil and Gas industry best practices will be observed in the Land Geophysical Safety Manual of the International Association of Geophysical Contractors (IAGC), an international trade association representing companies that provide geophysical services to the O\&G industry. In addition, articles published in the bulletins of the Brazilian Geophysical Society (SBGf) will be considered.

\section{Results}

The $E A D$, when using explosives as an energy source, are subject to registration of the Brazilian Army Command, in the Military Region (RM) where the seismic acquisition will occur, with the requirement to submit a PCE Safety Plan, prepared by a qualified professional and legally responsible. The security measures must prevent the occurrence of accidents that can endanger the integrity of people and property, as well as prevent deviations, misplacements, theft and robbery of explosives for illicit practice.

The activities of handling, transporting and storing explosives must occur under the supervision and presence of a blaster, with proven technical training and a license to exercise the function (ANP, 2012). In Maranhão state, the Superintendence of Criminal Investigation (SEIC), of the State Secretariat of Public Security, is responsible for issuing the license to handle explosives (blaster).

The local public security authorities should be previously communicated about the beginning of the seismic acquisition activities and the Emergency Response Plan (PRE) should contain the communication routine for emergencies, with the identification of all necessary contacts, including external support such as the Fire Department, SAMU, Civil and Military Police, the nearest health units, among others. In the emergency procedures, routines must be foreseen in case of fire or explosion, invasion of the explosive's storage and theft, loss and misplacement of explosives.

The councils of the municipalities covered by the seismic program shall issue a declaration that there is no impediment to the detonation service and provide a permit for the location and operation of the explosive's depots.

All persons involved in activities with explosives should receive specific guidance and training regarding the risks that are exposed, in accordance with the regulatory standards of the current Labor Inspection Secretariat, linked to the Ministry of Economy. In addition to providing training in Health, Safety and Environment (HSE), focused on operational procedures, work instructions, environmental risks, among others, the EAD should promote, when necessary, a training course of Blaster for the professionals selected to perform such a function.

The selection of personnel must be solid, with proof of the person's suitability being provided by means of an analysis of criminal records and the presentation of certificates supplied by the courts. Preferably, professionals registered in EAD's human resources database and with previous experience in seismic acquisition projects are hired. Newly hired personnel are required to present a reference letter issued by a company or professional stating the experience with the use of explosives and the suitability of the candidate.

\section{Storage conditions}

To perform the storage activity, EAD provides the construction of an explosives warehouse to be submitted to the inspection of the Controlled Products Inspection Service (SFPC) of the Brazilian Army, during the application process for the Registration Certificate (CR). In addition, the authorization for the acquisition of explosives is also conditioned to the existence of a storage facility registered with the Brazilian Army.

The type of deposit to be installed depends on the operational strategy of the seismic team. In general, is adopted temporary mobile deposits, which are special constructions that allows to move from one place to another, accompanying the change of location of the seismic acquisition teams. Figure 1 shows the mobile temporary storage with container installation.
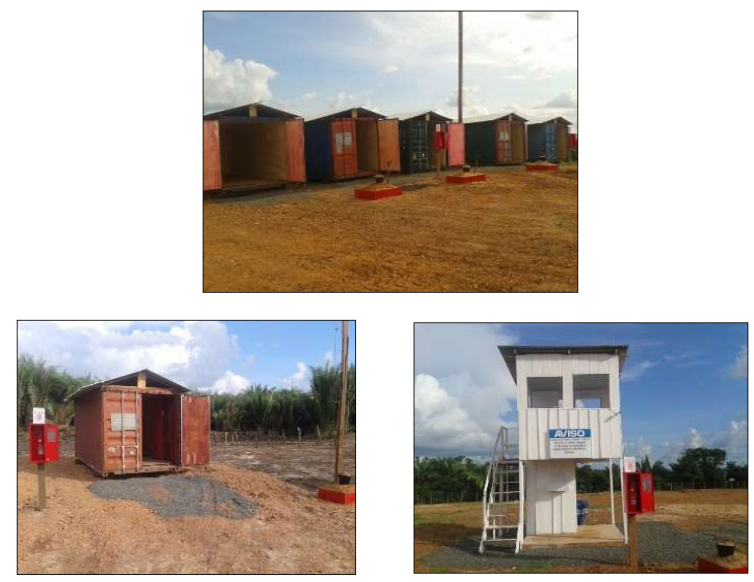

Figure 1. Mobile temporary storage with container - security box and separate storage locations for explosives and accessories.

Another solution adopted for the mobile temporary storage is to use a box truck with separate compartment for the accessories, as shown in Figure 2. However, the quantity of explosives stored shall be according to the capacity of the vehicle and the storage period may be limited by the SFPC. 


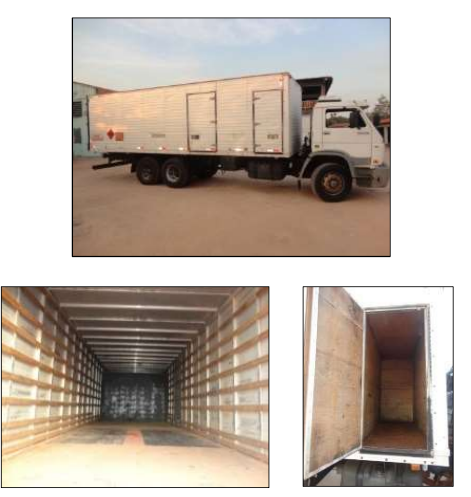

Figure 2. Box truck with separate compartments for storing explosives and accessories.

The area of storage has to be firm, dry, safe from flooding and away from urban centers, towns and areas with a concentration of dwellings, but located at a maximum distance from the base of operations or the nearest point of support to the seismic team, so that the journey time allows an agile service in emergency situations. The location should be chosen in rural area, within private property, with exclusive and restricted access routes and mobile phone coverage. A lease contract must be made with the owner of the land who will issue a declaration of authorization for the storage of explosives on his property.

The premises of the mobile temporary storage are composed of two separate storage areas, since the storage of explosives with initiating accessories (fuzes) is not allowed, a security guardhouse, and the storage place for the explosive boxes.

The size of the land is determined by the layout of the facilities and the minimum distance between the depots, determined by the maximum number of explosives that can be stored. In addition, safety distances from inhabited buildings, railways and roads must be respected.

The deposit fence should be with wire mesh or barbed wire. From the fence to the outside, a zone of clean land must be maintained, to avoid the approach of strangers and serve as a firebreak in case of burning of the surrounding vegetation..

Normally, the deposit does not have any infrastructure or supply network, either electric power, drinking water or sewage network. Therefore, drinking water is periodically supplied by cans or water tankers, and the sanitary effluent must be disposed in a septic tank. The solid residues are collected and stored in the Temporary Waste Storage Center (CATRE) of the seismic team until their final disposal, complying with the standards established by the current environmental legislation.

The electric power facility must be through solar panels or power generators only to feed the Closed-circuit TV (CCTV) for monitoring through internet link. In the radio room of the base of operations there will be the support of a radio operator and monitors with access to the warehouse surveillance cameras.

In addition to mobile telephony, communication is made by landline telephone via the internet and an integrated system of radio communicators and repeaters. In case of a power outage in the warehouse, communication is guaranteed by the availability of batteries.

For safety against fire and panic, the technical standards of the Fire Department of Maranhão and the Brazilian Association of Technical Standards must be observed. The mobile temporary storage facility must have an Atmospheric Discharge Protection System (SPDA), fire extinguisher distribution, alarm and emergency signaling. $E A D$ has the obligation to compose a Fire Brigade in accordance with the applicable legislation and standards.

The patrimonial security of the deposit and the armed escort of the transport must be made by specialized company, since such activity requires a very specific knowledge, besides being subject to numerous legal obligations. Armed security guards watch the entire storage area and control the entry and exit of authorized persons, through the registration in the access book to the warehouse. Access is restricted to employees working on site or of people previously authorized on a list with the identification of personal data and photographic record.

Before entering the area, everyone must be aware that smoking, carrying lighters or matches, flashlights, watches or any metallic object or tool capable of generating static electricity or sparks is forbidden. The use of cell phones and radio communicators, except for intrinsically safe ones, is forbidden within 50 meters of the explosives and electric fuzes storage areas. The surroundings and the interior of the storage area must have warning signs.

The responsible blaster for the storage must be available at the deposit during operational hours, being responsible for carrying out daily verification of all necessary and mandatory control items to ensure full compliance with the normative requirements of the Brazilian Army.

The activities of receipt, delivery or return of products are performed preferably in daylight. All internal transfers of explosive materials, must occur in the presence of the responsible blaster for each activity and by filling out a registration report.

Only vehicles involved in the transport and delivery of the explosives supplier can enter the warehouse area. Other vehicles used for the transport of visitors, whether for maintenance or inspection, remain in an area intended for parking outside the perimeter bounded by the fence.

The deposit maintenance or cleaning activities can only be carried out with the permanent monitoring of a Occupational Safety Technician or blaster, after carrying out the Preliminary Risk Analysis (APR) and the issuance of Temporary Work Permit (PTT).

In the process of demobilization of the seismic team, the remaining unused explosives and accessories shall be destroyed, with the issuance of the PCE destruction report, or transferred to another active EAD facility. The explosives deposit shall be deactivated by removing all installations for the delivery of the land under the same original conditions, without causing environmental or of any nature, by issuing a declaration of delivery of the property signed by the owner. The demobilization report of the deposit must contain the photographic record of the 
deactivation of the facilities and be filed in the SFPC, and later delivery to the ANP as an attachment to the final geophysical survey report.

\section{Transport and distribution of explosives}

The operational logistics of seismic acquisition in the Parnaíba Basin are made possible by land transport, using $4 \times 4$ vehicles, since most of the local roads are unpaved, which makes traffic difficult, especially during rainy periods.

Transportation is a critical factor of the activity, both to make the operation viable and for the safety of all involved. Therefore, the vehicles must be adequate to the needs of use and always in excellent mechanical condition.

The vehicle body must be closed, box type, with a separate compartment for fuzes (initiating accessories), where a safety box with steel plate armor will be installed. Figure 3 shows a vehicle adapted and licensed for the transport of explosives and accessories.
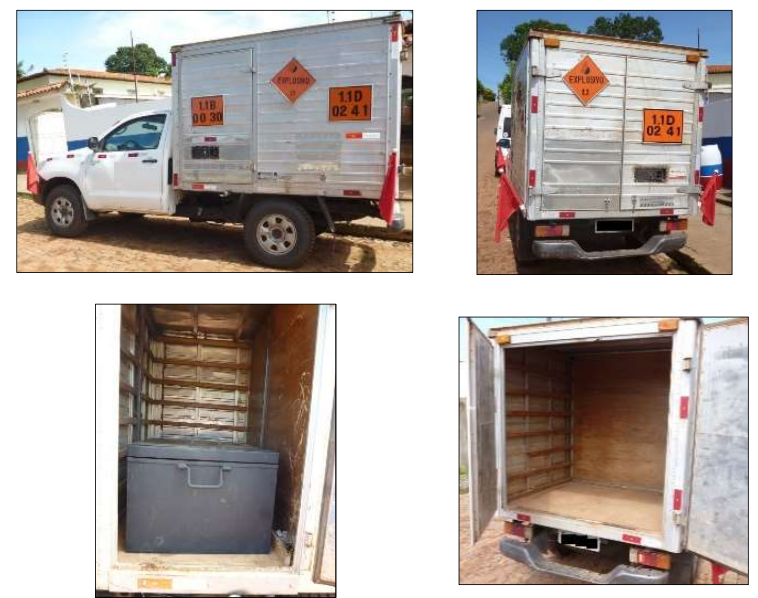

Figure 3: Vehicle for transporting explosives and accessories.

The vehicles used in the transport of explosives are provided with adequate signaling, with risk labels, safety panels, and other applicable symbols, visibly affixed, according to the Complementary Instructions to the Land Transport Regulations for Dangerous Goods from the National Land Transport Agency (ANTT).

The explosives transporting team is composed of a driver and a blaster and must be mandatorily accompanied by an armed escort. The driver must have a course on Operational Handling of Dangerous Products (MOPP), according to the standards on the training process for drivers of motor vehicles established by the National Transit Council (CONTRAN).

Transportation should be carried out, preferably in daylight, always accompanied by the traffic guide issued by the Army, from origin to destination, and subject to surveillance throughout the entire journey. The routes are programmed in a rotogram, avoiding traffic in urban areas and places subject to theft or accidents, mainly at times of greater flow and congestion. Refueling shall be avoided when the vehicle is loaded with explosives.
The responsibility for explosives distribution to the loading team is the responsible blaster of the transport, by filling in the report of registration of the transfer. The amount of explosives transported is established by the daily schedule of loading, always in order to avoid leftovers at the end of the working day. If there is no consumption of all explosives and accessories at the end of the loading activities, the surplus will be returned to the transport and, consequently, to the stock of the deposit, observing the strict count and the proper completion of the registration reports.

Figure 4 illustrates the distribution of explosives and accessories, with the accompaniment of the armed escort and the delivery of explosives to the loading team. The vehicle shall be parked in a place away from dwellings.

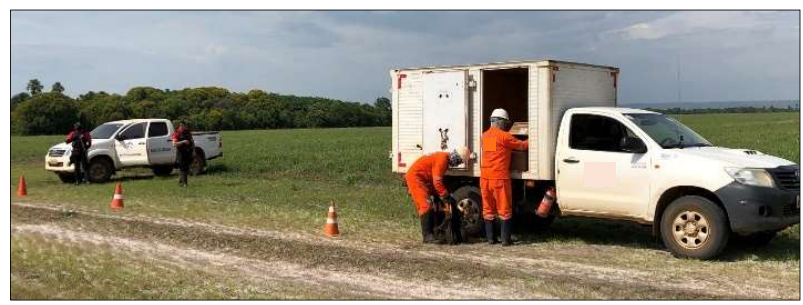

Figure 4. Transport and distribution of explosives and accessories with armed escort.

The loading and unloading operations are carried out with the vehicle switched off, and the fuzes (starting accessories) will always be unloaded first, before the explosives, as opposed to the loading of the vehicle, where the fuzes are loaded last. In the discharge operation, the explosives shall not be stacked in the vicinity of the vehicle's discharge pipe (exhaust pipe), which shall be fitted with the flame arrester.

All vehicles transporting explosives and accessories must have a cell phone, intrinsically safe radio communicator (IS) and real-time tracking system via Global Positioning System (GPS). The monitoring of explosives transport is performed at the base of operations, through the radio operator, as well as the monitoring of the explosives warehouse cameras.

In case of accident or breakdown, the vehicle shall not be towed if it is loaded with explosives and accessories. If possible, remove the vehicle from the track and signal the location. Then inform to transit authority. In case of an accidents, the location must be signed and prioritize the removal of the starting accessories for a safe distance from other vehicles or dwellings. In case of fire, stop and park the vehicle, stop traffic and isolate the place.

\section{Operational activities with the application and handling of explosives}

Before proceeding with the operational aspects directly involved in the application and handling of explosives, it is necessary to highlight that the permitting team plays a key role in communicating with the landowners and the leaders of the communities involved in the project's area of influence.

Everyone should be well informed about the use of explosives in seismic acquisition and aware that EAD 
operates in legal compliance and adopts all necessary measures to preserve the environment and the safety of workers and third parties. The lectures in the communities are held to bring more knowledge and are an integral part of the actions of the Social Communication Plan (PCS) and of the environmental licensing conditions.

Another activity developed by the permit agents is mapping of springs and engineering works (buildings, improvements, wells, weirs, farm areas, fish farming ponds, transmission lines, pipelines, highways, railroads, among others) that allows the identification of interferences with the seismic lines, to propose the eventual deviation or displacement.

The Table of Minimum Safety Distances (TDMS) establishes the safety distances for engineering works and water bodies according to the parameters (quantity and depth of the holes and size of the explosive charge) of the shot point (SP) and environmental legislation. The Quality Control (QC) geophysicists are responsible for defining the TDMS distances and guiding all work fronts on the rules of SP displacement.

In onshore seismic acquisition, the detonation service is carried out in two distinct operational stages or fronts, called loading and detonation (seismic recording), due to the need to spread and overhaul seismographic equipment.

For the detonation service execution, the EAD must request an authorization for the SFPC, with the presentation of the Fire Plan, statements that there is no impediment to perform the service of detonation in the municipalities covered by the seismic lines and the Technical Responsibility Annotation (ART) of the service within the Confea/Crea System.

The Fire Plan will contain the map with the location of the 2D seismic lines that will be registered and the limits of the municipalities, the nominal list of those involved in the loading and detonation operations, the licenses of the blasters, and the list of the Serial Individual Identification (IIS) of the explosives and accessories that will be used.

The Brazilian Army and the ANP requires that the maximum time between the two operations be up to 72 (seventy-two) hours or 3 (three) days. In general, the loading of the SP is done as little time as possible before the detonation. As an additional safety measure, in cases where there is greater proximity to inhabited areas, the loading is postponed, to be simultaneous with the detonation.

Loading teams should be composed of at least two blasters. One of the blasters is the team leader, responsible for guiding and supervising all tasks, ensuring compliance with safety standards and maintaining daily control of explosives in the field, through the loading report. The other blaster is the primer, responsible for keeping the fuzes safe and performing the priming process, characterized by the coupling of the explosive and fuze set.

During transportation on the $2 \mathrm{D}$ seismic line site, the explosives must be packed in canvas bags or backpacks with a closing flap. Fuzes, on the other hand, should be transported in antistatic boxes made of wood and lined with aluminum. The bags and boxes must always be kept closed during the walk along the line, with special attention to the crossing of obstacles such as fences, ditches, and bodies of water. Figure 5 records the moment of some of the tasks performed by the loading team.
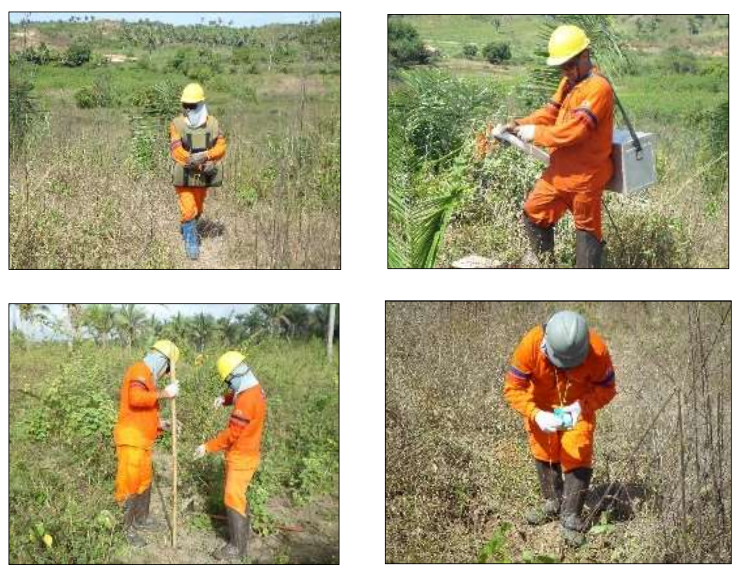

Figure 5: Loading - explosives transport, fuze transport and priming, tamping and galvanometer testing.

IAGC advises that fuzes should have their conditions tested through appropriate equipment. Therefore, a galvanometer must be used to measure the electrical continuity (resistance) of the wire-fuze circuit after its insertion in the ground, observing the reference values (standard range of values that varies with the length of the fuze wire) for short, normal or open. If the measured value is in the range of values for short or open, it means that the fuze is defective, or that the fuze wire broke, and the load must be recovered or destroyed.

After the loading of the hole, all interventions on the explosive charge can only be carried out with the issue of the PTT and by trained personnel accompanied by the Occupational Safety Technician.

At the end day, all reports produced in the field, whether from the warehouse, transport, or loading, are delivered to the stock controller and the HSE sector for the appropriate checks. Any discrepancies found must be clarified immediately.

The detonation crew performs the second and last stage of the detonation services and is part of the operational front called Seismography, and is composed of a shooter (blaster), who performs the operational procedures under the guidance of the Seismograph Observer. The explosive charge is only detonated through the radio signal emitted by the Observer.

Figure 6 shows, on the left, the operation of the blasting unit by the shooter positioned on the 2D seismic line and, on the right, the seismograph monitors installed in the box truck (known as the White House, in field jargon), where the Observer coordinates the seismography operations. 

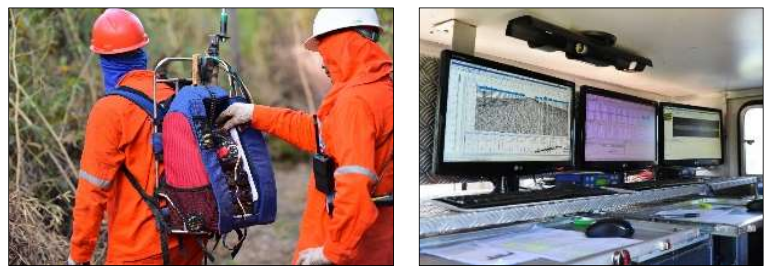

Figure 6: Seismography - detonation and recording the data in the seismograph.

Each detonation crew has whistles to make the warning sound at the time of blasting. In addition, a permit agent is assigned to monitor the seismography activities with the assignment to make alerts and contacts with landowners and local community members if necessary.

Finally, the area recovery (AR) operational front also performs the rechecking of explosive charges with the galvanometer, to ensure that all charges in the field was detonated, as well as the cleaning of the seismic line surroundings, with the removal of stakes, pickets, fuze wires, sign's materials and any residues that are in the field, and the tamponade of detonated shot point. All the holes are inspected to verify the existence of cavities produced by the detonation of the explosive charges.

After each field charge check, in the case of a finding or suspected presence of an explosive charge on the ground, the site must be signed and a field charge report issued.

Even with the use of degradable explosives, as determined by the ANP, the Brazilian seismic teams adopt the practice of not leaving charges on the ground. The unexploded charge represents a non-conformity, and every effort should be made to remove it, destroy it, or ensure that it does not offer future risks.

\section{Conclusions}

This work presented the main safety measures for the legal framework and the prevention of accidents in handling, transport and storage of explosives in the provision of onshore seismic acquisition services for the oil and gas exploration in the Parnaíba Basin, State of Maranhão, from the experience in several projects carried out and field observation.

According to this, it was possible to prepare a material with guidelines on the use of explosives and accessories, meeting the provisions of the latest Brazilian Army Regulation of Controlled Products, known as R-105, and the requirements established by the ANP, contributing to the continuous improvement of the operational procedures of the Brazilian onshore seismic acquisition crews in the prevention of accidents.

\section{Acknowledgments}

We would like to thank the company Eneva S.A. for promoting the onshore seismic acquisition activity in Brazil, being responsible for approximately $25,000 \mathrm{~km}$ of $2 \mathrm{D}$ seismic data and $470 \mathrm{~km}^{2}$ of 3D seismic data, contributing to the increase in the geological knowledge of the Parnaiba Basin.

\section{References}

NATIONAL PETROLEUM, NATURAL GAS AND BIOFUELS AGENCY (ANP). Resolution ANP $n^{\circ} 3$, of January 18, 2012. Rio de Janeiro, RJ, jan. 2012.

Annual Report on Operational Security of Oil and Natural Gas Exploration and Production Activities: 2019. Superintendency of Operational Safety and Environment (SSM), 2020.

BRAZIL. Decree $n^{\circ}$ 10,030, of September 30, 2019. Approves the Regulation of Controlled Products. Brasília, DF, 2019.

BRAZILIAN ARMY. Ordinance $\mathrm{n}^{\circ} 56$-COLOG, of June 5 2017. It provides for administrative procedures for granting, revalidation, apostille, and cancellation of registration in the Army for the exercise of controlled product activities and other provisions. jun. 2017.

Ordinance No. 147-COLOG, of November 21 2019. Provides on administrative procedures for the exercise of activities with explosives and their accessories and products containing ammonium nitrate. nov. 2019.

INTERNATIONAL ASSOCIATION OF GEOPHYSICAL CONTRACTORS (IAGC). Land Geophysical Safety Manual. 10. ed. Houston: 2012.

VIANNA, R. B. Panorama of Security of Seismic Teams in Brazil. SBGF Bulletin - Security in ground seismic teams. n. 89. p. 21-23. Rio de Janeiro: Brazilian Society of Geophysics, 2014. 